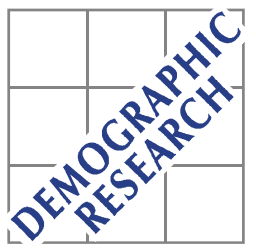

Demographic Research a free, expedited, online journal

of peer-reviewed research and commentary in the population sciences published by the Max Planck Institute for Demographic Research

Konrad-Zuse Str. 1, D-18057 Rostock · GERMANY

www.demographic-research.org

DEMOGRAPHIC RESEARCH

VOLUME 17 ARTICLE 6, PAGES 135-156

PUBLISHED 12 OCTOBER 2007

http://www.demographic-research.org/Volumes/Vol17/6/

DOI: 10.4054/DemRes.2007.17.6

Research Article

Understanding parental gender preferences in advanced societies:

Lessons from Sweden and Finland

Gunnar Andersson

Karsten Hank

Andres Vikat

(C) 2007 Andersson, Hank \& Vikat

This open-access work is published under the terms of the Creative Commons

Attribution NonCommercial License 2.0 Germany, which permits use, reproduction \& distribution in any medium for non-commercial purposes, provided the original author(s) and source are given credit.

See http:// creativecommons.org/licenses/by-nc/2.0/de/ 


\section{Table of Contents}

1 Introduction 136

$2 \quad$ Theorizing parental gender preferences 137

3 Study populations, data, and method 141

$4 \quad$ Results 143

4.1 Differences in parental sex preferences among national 143

4.2 Regional and educational differences in parental sex 146 preferences among the native-born population in Sweden

5 Discussion 150

6 Acknowledgements 151

References 152 


\title{
Understanding parental gender preferences in advanced societies: Lessons from Sweden and Finland
}

\author{
Gunnar Andersson ${ }^{1}$ \\ Karsten Hank ${ }^{2}$ \\ Andres Vikat ${ }^{3}$
}

\begin{abstract}
Extending recent research on parental gender preferences in the Nordic countries, this study uses unique register data from Finland and Sweden (1971-1999) that provide us with the opportunity to compare childbearing dynamics and possible underlying sex preferences among native majorities and national minorities, namely Finnish-born immigrants in Sweden and members of the Swedish-speaking minority in Finland. For Finland, we observe a continuous boy preference among the national majority and the Swedish-speaking minority as reflected in higher third-birth rates of mothers of two girls than of mothers of two boys. Evidence of similar preferences is found for Finnishborn migrants in Sweden, where the native-born population instead appears to have developed a girl preference. In all cases, we also observe clear indications of a preference for having at least one child of each sex. Generally speaking, our findings support an interpretation of parental gender preferences as a longstanding cultural phenomenon, related to country of childhood socialization rather than language group. Moreover, an analysis of regional and educational differentials in child-sex specific fertility behavior in Sweden reveals no evidence which supports various diffusion theories of persistence and change in parents' sex preferences for children.
\end{abstract}

\footnotetext{
${ }^{1}$ Stockholm University, Stockholm. Email: gunnar.andersson@ sociology.su.se.

${ }^{2}$ MEA - University of Mannheim \& DIW Berlin. Email: hank@mea.uni-mannheim.de.

${ }^{3}$ United Nations Economic Commission for Europe, Geneva. Email: andres.vikat@unece.org.
} 


\section{Introduction}

'The desire for a son is the father of many daughters' (Seidl 1995) it says - which is likely to explain much of demographers' longstanding interest in parental gender preferences. Attention for this topic has also been growing rapidly in recent studies on advanced western societies (e.g., Diekmann \& Schmidheiny 2004; Hank \& Kohler 2000; Lundberg 2005; Marleau \& Saucier 2002; Raley \& Bianchi 2006). This development might, first, be due to medical advances that facilitate parents' deliberate choice of their child's sex (e.g., Dahl et al. 2003, 2006). Secondly, it has been argued that in modern low-fertility societies the influence of the sex composition of previous children on couples' childbearing behavior might intensify, because factors affecting the decision to have another child should become more important (e.g., Gray \& Evans 2005; Sloane \& Lee 1983).

Most empirical evidence suggests an almost universally dominant pattern of parental sex preferences favoring at least one child of each sex (e.g., Arnold 1997; Hank \& Kohler 2000). Although it has been claimed that changes in a society's gender system may lead to a decreasing effect of children's sex on parents' fertility decisions (Pollard \& Morgan 2002), recent studies have shown that modernization and increasing gender equality do not necessarily bring about parental gender indifference. The Nordic example (cf. Andersson et al. 2006) ${ }^{4}$ shows, that, on the one hand, new sex preferences (in favor of girls) are likely to have evolved in Denmark, Norway, and Sweden as recently as in the 1980s, while, on the other hand, culturally rooted preferences for sons in Finland have been left unaffected by improvements in women's social, political, and reproductive rights (see Dahl \& Moretti, 2004, for related evidence from the US).

This paper extends recent research by Andersson and colleagues (2006) in two ways. First, it proposes to improve our theoretical understanding of parental gender preferences in advanced societies - and recent changes therein - by accounting better for the possible role of social interaction, culture, and national institutions (Section 2). Second, it makes use of unique register data from Finland and Sweden for the period 1971-1999 (see Section 3), providing us with the opportunity to compare childbearing dynamics - and sex preferences for children that may drive these - among native majorities and national minorities, namely Finnish-born immigrants in Sweden and members of the Swedish-speaking minority in Finland (Section 4.1). The study is achieved by means of comparing differentials in parents' family building by the sex composition of their previous off-spring. Moreover, our Swedish data set allows us to investigate regional and educational differences in fertility behavior and possible

${ }^{4}$ See Brunborg (1987), Jacobsen et al. (1999), Kartovaara (1999), and Schullström (1996) for earlier investigations of sex preferences for children and fertility decisions in the Nordic countries. 
preferences of two-child mothers from 1981 onwards (Section 4.2). The concluding section connects our considerations and empirical findings (Section 5).

\section{Theorizing parental gender preferences: The role of social interaction, culture, and institutions}

A major shortcoming of most studies investigating sex preferences is their relatively weak theoretical foundation, particularly if they deal with more developed societies (e.g., Hank \& Kohler 2003: Section II; see also Lundberg 2005). In this paper, we suggest several basic mechanisms, through which sex preferences for children may be reproduced or changed. The first two are closely interrelated, namely (1) social interaction and (2) culture. Another mechanism proposed here refers to (3) national institutions, particularly such related to information and welfare-state systems (cf. Brockmann 2001; Andersson et al. 2006).

The concept of social interaction can be fruitfully applied to the topic of our study, especially if we are trying to understand better sudden changes in previously longstanding preferences (cf. Andersson et al. 2006; Pollard \& Morgan 2002). Social interaction may either serve as a channel for innovative interpersonal communication, facilitating the flow of information, or as conservative cultural forces, encouraging adherence to behavioral norms. Using the language of Montgomery \& Casterline (1996), the former can be called social learning, while the latter can be described as social influence.

With regard to social learning, Bongaarts \& Watkins (1996) distinguish the exchange of information and ideas on the one hand from the joint evaluation of their meaning in a particular context on the other hand. They suggest that social interaction processes take place at different levels of aggregation: "Just as personal networks connect individuals, so channels of social interaction connect social and territorial communities within a nation, and nations within the global society. Through these channels, actors at these three levels exchange and evaluate information and ideas, and exert and receive social influence" (Bongaarts \& Watkins 1996: 665).

Besides 'interpersonal communication', Montgomery \& Casterline (1996: 154f.) explicitly account for those forms of social interaction, where "the information set is shaped by communications emanating from impersonal sources, such as the mass media, markets, and other aggregate social structures." There has been much debate about the influence of mass media on fertility (e.g., Westoff 1999; see also Stark \& Kohler 2002), where modern means of communication are generally perceived to foster social change and to reduce, for example, regional differences in behavior. This does not imply, though, that the evolution of new preferences or the continuation of 
traditional behavior may not vary anymore between nations or across various subpopulations within a single country.

Different from the 'direct' transmission mechanism of social interaction, cultural normative patterns will rather be determined by individuals' internalization of basic normative attitudes and values at various stages during their life course. Hammel (1990: 475), for example, argues for "a view of culture that [recognizes] the agency of individuals in using behavior as symbol selected from a repertoire that has some coherence and endures over time, but that is created and maintained by patterns of selection by actors as well as innovation." From this, Hammel (1990: 467) develops a notion of culture as "an intensely evaluative cloud of comments", where culture provides the normative and interpretative rules, according to which individuals consider their fertility (and/or sex) preferences. However, individuals may be subject to different contextual influences over time, and thus individual behavior can be influenced by lagged as well as by contemporaneous contextual effects (see, for example, Axinn \& Yabiku 2001).

But more specifically: why should parents at all prefer having children of one sex over having children of another sex? It is generally argued that children of a particular sex are desired to provide certain utilities, such as financial, social, or psychological benefits. In developing countries, for example, sons are presumed to have greater economic net utility than daughters, since male offspring is better able to provide assistance in agriculture and to serve as a simple social security system. In patrilineal societies sons are also valued for continuing the family name. Daughters, on the other hand, should be more reliable in providing old-age assistance. In addition, they are frequently desired to help with household tasks or to care for younger siblings. Thus, even in countries with a prevailing preference for sons, many families consider it important to have at least one daughter (e.g., Arnold 1997; Cleland et al. 1983).

In industrialized societies children no longer provide economic net utility, but have rather become a source of significant time and monetary costs. However, Hoffman \& Hoffman (1973) list a set of alternative values that parents may still attribute to their children, such as expansion of the self, affiliation, stimulation, accomplishment, or social comparison (cf. Thomson 2001). At least with regard to some of these categories, different benefits may accrue from daughters or sons for each of the partners. Morgan et al. (1988), for example, have argued that boys might reduce parents' divorce risk, since fathers' attachments and obligations to their children, and marital cohesion, are greater if they have sons (see Diekmann \& Schmidheiny, 2004, for a recent discussion of this father-involvement hypothesis). Women, on the other hand, may consider girls as easier to be raised or as more rewarding companions (e.g., Marleau \& Saucier 2002). Since each partner might want to have a child of his or her own sex, couples may desire - and be better off with - a gender mix. This argument corresponds with empirical research 
on divorces in Sweden showing a slightly reduced divorce risk of two-child parents that have one child of each sex (cf. Andersson and Woldemicael 2001). Last but not least, it has been shown that parity matters a great deal, if parental gender preferences are considered. Results of a study analyzing values and disvalues attached to children in the Philippines, Korea, and the United States, for example, suggest that balancing of the family's sex composition is most important for family building when the decision to have a third or a fourth child is considered, while general emotional and psychological rationales for having a child at all dominate at lower parities (Bulatao 1981).

The role of institutions in changing sex preferences for children has been stressed by Pollard \& Morgan (2002), who contend that more equal opportunities for women and men (induced by changes in the societal 'gender system') should result in a decreasing effect of children's sex on parents' fertility decisions (see also Bongaarts 2001: 277). This argument, however, has not been left undisputed. Recent evidence from the Nordic countries (Andersson et al. 2006) strongly suggests that modernization does not necessarily neutralize gender preferences, but that in some cases traditional values attached to sons may retain a foothold while elsewhere new sex preferences might evolve. Along the same lines, Brockmann (2001: 199) argues that, for example, "increasing female labour-force participation and the growing 'burden of ageing' should increase the value of a daughter, since she assumes both the role of a breadwinner and that of a caregiver." Moreover, changing expectations concerning the division of labor and family responsibilities between men and women (Bianchi et al. 2000; Hank \& Jürges 2007), followed by a more positive evaluation of women's role in society, might rather foster the development of a preference for girls (e.g., Hammer \& McFerran 1988) than parental gender indifference, as proposed by Pollard \& Morgan (2002).

Unfortunately, there is a huge gap between the fundamental significance of institutions, patterns of social interaction, and culture on the one hand, and the empirical limitations to identify the nature of the underlying mechanisms that are supposed to influence individual fertility preferences on the other hand. Observed outcomes in terms of family demographic behavior and vital events can usually be generated by many different processes, but outcome data typically have only limited power to distinguish among alternative plausible hypotheses regarding these processes (cf. Manski 1995). Moreover, Axinn \& Yabiku (2001: 1225) argue that there may be independent effects of childhood and adult social contexts on adult decision making: "[S]ocial context during childhood affects social organization in the child's family, which subsequently influences childbearing behavior in adulthood. Mechanisms affecting the costs and benefits of childbearing, however, operate during adulthood as a person decides on childbearing. Mechanisms linked to the diffusion of [...] ideas may operate through either childhood or adult processes [...]." 
In this paper, we make an attempt to tackle some of the processes suggested to drive continuity and change in parental gender preferences by comparing differentials in childbearing dynamics by the sex composition of existing children among various population subgroups (national minority, regional, educational) in Sweden and Finland. Although some studies (e.g., Hank and Kohler 2003; Marleau and Saucier 2002) have shown that sex preferences even for firstborn children may well exist in Western societies, we do not expect to find behaviorally relevant sex preferences among mothers of one child in any of the groups represented in our study, because for those women the main consideration should merely be whether or when to have an additional child (see also Andersson et al. 2006). With regard to potential differences we propose the following set of four hypotheses:

(a) Assuming that longstanding cultural normative patterns - which the individual internalized during childhood and which thus continue to work independently of subsequent processes of social learning or social influence - matter, we hypothesize that Finnish-born migrants living in Sweden will tend to exhibit sex preferences similar to those of the non-migrant Finnish population. However, we may also find differences within the migrant population, namely between those who moved to Sweden early during childhood and those who migrated later during their life course. Because the former were regularly exposed to social interactions with Swedish peers before entering adulthood, they are likely to have 'learned' about fertility (and sex) preferences in the native population, possibly adopting these for themselves. This is unlikely to be the case (or only limited so) for 'late' adult migrants.

(b) Considering the generally high degree of socio-demographic and socioeconomic similarities (see below) and the sharing of the same national context during childhood and adulthood, we hypothesize that there will not be any substantial differences in parental gender differences between the Swedish-speaking minority and the majority population in Finland. An alternative hypothesis, though, refers to the idea that the Swedish minority community - living in the Finnish coastal regions for centuries - may exert a relatively strong social influence on its members (cf. Finnäs 1997: 274). If different sex preferences were present historically, such influence could serve as a conservative cultural force, preserving these differences and preventing an equalization of behaviors. In addition, if innovations in social behavior tend to follow linguistic barriers rather than national borders (cf. Watkins 1990), we would expect the Swedish-speaking minority to be more likely to pick up behaviors observed for the majority population of Sweden.

(c) Because urbanites have often been suggested to act as forerunners of social change (e.g., Wirth 1938), we hypothesize that mothers living in the capital area of Sweden will tend to exhibit less 'traditional' gender preferences (potentially more often 
favoring daughters over sons), or develop any daughter preference observed for the general population earlier than their non-metropolitan counterparts.

(d) Because education may be rendered an important determinant of attitudes towards women's role in society, one might assume a greater prevalence of 'modern' preferences (potentially favoring daughters over sons) among the more highly educated. ${ }^{5}$ More specifically, making - again - a diffusion argument, we hypothesize that any new girl preference in Sweden developed earlier and/or more intensely among the more highly educated mothers than in the less educated population.

\section{Study populations, data, and method}

In Finland, the Swedish-speaking minority has roots going back many centuries (for details see e.g. Finnäs 1997; 2003). When Finland was still part of the Swedish realm, Swedish was the dominant official language in government, business, and culture. Today, Swedish and Finnish have an equal status as official languages. For example, in the educational system - from elementary schools to universities - Swedish and Finnish language institutions exist in parallel. Similarly, a variety of Swedish mass media (television, radio, newspapers) is easily accessible. About six percent of the Finnish population is Swedish-speaking, being geographically concentrated along the western and southern coastline. About half of the Swedish-speaking persons live in municipalities where they form the local majority. Another fifth of the Swedish minority lives in metropolitan areas, where their proportion of the total population is less than ten percent.

Although differences in socio-economic status and education between the Finnishspeaking majority and the Swedish-speaking minority are generally very small, the latter is still overrepresented in white-collar occupations and underrepresented among manual workers. Similarly, demographic behavior generally differs more between regions in Finland than between language groups. ${ }^{6}$ However, the Swedish-speaking minority is on retreat: during the 1950s and 1960s substantial emigration to Sweden was observed, concurrent with a doubling of the Finnish-speaking population in the main Swedish settlement areas between 1950 and 1980. Also, since the mid-1970s, the number of linguistic intermarriages has outnumbered the unilingual Swedish ones.

\footnotetext{
${ }^{5}$ Although recent evidence from Germany suggests a higher propensity of the more highly educated to favor daughters, the rare overall empirical evidence about the relationship between parents' education and their sex preference for children remains unclear (cf. Hank \& Kohler 2003).

${ }^{6}$ See, however, Finnäs' (1997) study on divorce. The author finds remarkably lower divorce rates among the Swedish-speaking minority than among the Finnish-speaking majority, suggesting that this might be a result of better social integration among the former group.
} 
In Sweden, immigrants from Finland comprise the by far largest single foreignborn group (e.g., Svanberg \& Runblom 1988). In addition to the shared history of the two nations, there are geographical and economic reasons for this. Finland, which is Sweden's nearest neighbor to the east, lagged behind economically before finally catching up during the 1980s. This led to a large flow of labor migrants from Finland to Sweden, which was facilitated by the existence of a free Nordic labor market and slowed down only during the late 1970s to early 1980s, following the equalization in the living standards of the two countries. One result of the long intertwined migration history is that many Finnish-born women have become partners of Swedish-born men. For a detailed description of fertility patterns of immigrant women in Sweden, see Andersson 2004; Andersson \& Scott 2005; 2007.

Statistics on events to and characteristics of the native and foreign-born resident populations are collected and summarized by the Statistical Central Bureaus of Finland and Sweden, from whose population register systems the data for our calculations are derived (cf. SCB 2003; Wallgren \& Wallgren 2007). The population-registration systems have been computerized since the end of the 1960s and have a long history of full and reliable coverage of the local populations and their vital events. We use data on live births and the corresponding exposure times of risk for various subgroups of women - defined by parity, country of birth (Sweden), language group (Finland), region of residence (Sweden), and education (Sweden) - to calculate multivariate models of parity-specific birth risks by the sex composition of previous children. These occurrences and exposures are derived from the longitudinal information on the dates of each recorded birth of all women in Sweden and a 10\% sample of women in Finland who were born in 1935 and 1937, respectively, and onwards. The data extracts that we have used include information on every such individual who had ever been resident in the respective countries in 1971-1999.

We estimate proportional-hazards models, whose results are presented as standardized relative risks of second and third births by the sex of the previous child or children for mothers in each of the two countries. The main explanatory variable is the sex of the previous child (for second births) or children (for third births). We regard any observable differences in parity-progression risks by that sex composition as a reflection of parents' gender preferences for children, assuming that parents are more likely to continue childbearing if they have not acquired their desired number and/or sex composition of children. We use calendar year (defined as a dummy variable depicting period effects in fertility by single calendar years) as another main variable of interest. By running an interaction between the sex of the previous child or children and calendar year, we aim to detect changes and continuities in parents' gender preferences for children. We present period trends in parity-progression risks for the years 19711999. We use age of mother (ranging from 15 to 44 years in seven age groups) and time 
since the previous birth (ranging from 0 to 10 years in six groups) as control variables in our analyses. All variables are treated as grouped categorical covariates. Table 1 provides basic descriptive statistics on our study populations of one- and two-child mothers in the two countries. They refer to mothers born and residing in Sweden and Finland, respectively, as well as mothers born in Finland but residing in Sweden, and Swedish-speaking mothers born and residing in Finland.

Table 1: Descriptive statistics - Study populations of Finland and Sweden, 1971-99

\begin{tabular}{lrrrr}
\hline & $\begin{array}{r}\text { Woman-years } \\
\text { as one-child } \\
\text { mother }\end{array}$ & $\begin{array}{r}\text { Number of } \\
\text { second } \\
\text { births }\end{array}$ & $\begin{array}{r}\text { Woman-years } \\
\text { as two-child } \\
\text { mother }\end{array}$ & $\begin{array}{r}\text { Number of } \\
\text { third births }\end{array}$ \\
\hline Finland & 373,800 & 57,000 & 436,900 & 22,100 \\
Swedish minority in Finland & 17,600 & 3,000 & 23,900 & 1,200 \\
Sweden & $4,996,500$ & 900,100 & $7,112,800$ & 343,300 \\
Finnish-born migrants in Sweden & 239,800 & 34,000 & 296,500 & 13,800 \\
\hline
\end{tabular}

Source: Finnish and Swedish population registers, authors' calculations.

\section{Results}

\subsection{Differences in parental sex preferences among national majorities and minorities in Finland and Sweden}

Our first set of analyses compares childbearing dynamics among Finnish and Swedish native-born populations, members of the Swedish-speaking minority in Finland, and Finnish-born immigrants in Sweden across the entire observation period 1971-1999, estimating separate models for one- and two-child mothers (see Table 2; also compare the results reported in Andersson et al. 2006).

A statistically significant association between the sex of the first child and second birth risks is observed only among the Finnish majority population, where the slightly lower risk $\left(0.98^{7}\right)$ of having another child after the birth of a son suggests a behaviorally relevant preference for boys. This finding is corroborated by the lower risk (0.92) of Finnish natives to experience a third birth after having had two boys (vs. having had two girls). Despite considerable fluctuations in the magnitude of these 'gendered' third-

${ }^{7}$ A relative risk of 0.98 means that the second-birth intensity (for mothers of one boy) is two percent lower than that of mothers belonging to the reference category (mothers of one girl). 
birth intensities between single calendar years, Figure 1 depicts no systematic variations - that would suggest changes in Finnish parents' son preference - across time. Moreover, we detect a preference for a mixed composition of Finnish parents' offspring, which is substantially stronger, though, if the firstborn children are both girls (1.28) rather than being two boys (1.17).

The Swedish-speaking minority in Finland exhibits a pattern similar to the one observed for the entire Finnish population, but the child-gender effect on continued childbearing is only statistically significant ${ }^{8}-$ at the five-percent level - when mothers of two girls are compared with mothers of one boy and one girl, where the former exhibit a 1.23 times higher risk of having another child.

Turning to Finnish-born migrants in Sweden, we also find that childbearing dynamics here do not differ from those observed in Finland. There is clear evidence pointing to a son preference in this immigrant group: having two boys instead of two girls reduces the probability of having a third child (0.95); the strong preference for a mixed sex composition among one's offspring is gender biased, i.e., third birth intensities are highest among mothers of two girls (1.24 vs. 1.18 among mothers of two boys).

The native-born population of Sweden shows a - compared to Finns - reverse association between the sex of previous children and continued childbearing. The probability of experiencing a third birth is highest for mothers who already gave birth to two boys (1.27 vs. mothers of mixed offspring), and among those with two same-sex children the propensity to continue childbearing is significantly higher if those children are male (1.05). In other words: there is clear indication of a girl preference (at higher parities) in the Swedish population. Although somewhat higher third-birth intensities among mothers of two sons can already be observed for the 1970s, a more stable girl preference evolved only from the mid-1980s onwards (see Figure 1).

\footnotetext{
${ }^{8}$ Note that the study population of a ten-percent sample of Swedish-speaking mothers in Finland is not much larger than that of any ordinary demographic sample-survey data.
} 
Table 2: Relative risk of giving birth to another child for one- and two-child mothers, respectively, in Finland and Sweden, 1971-99, by sex composition of previous children

\begin{tabular}{lcccc}
\hline & Finland & $\begin{array}{c}\text { Swedish-speaking } \\
\text { minority in Finland }\end{array}$ & $\begin{array}{c}\text { Sweden } \\
\text { Finnish-born } \\
\text { migrants } \\
\text { in Sweden }\end{array}$ \\
\hline $\begin{array}{l}\text { Second-birth risks of mothers of: } \\
\text { - one boy vs one girl }\end{array}$ & 0.98 & $(0.95)$ & $(1.00)$ & $(0.99)$ \\
Third-birth risks of mothers of: & & & & \\
- two girls vs one boy and one girl & 1.28 & 1.23 & 1.21 & 1.24 \\
- two boys vs one boy and one girl & 1.17 & $(1.12)$ & 1.27 & 1.18 \\
- two boys vs two girls & 0.92 & $(0.92)$ & 1.05 & 0.95 \\
\hline
\end{tabular}

Source: Finnish and Swedish population registers, authors' calculations. Results are standardized for calendar year, age of mother, and time since previous birth.

Note: effects that are not significant on a five-percent level are given in parentheses.

Figure 1: Relative third-birth risks in Finland and Sweden, by sex of the first two children, 1971-99: Risks for mothers of two boys relative to those of mothers of two girls in each calendar year

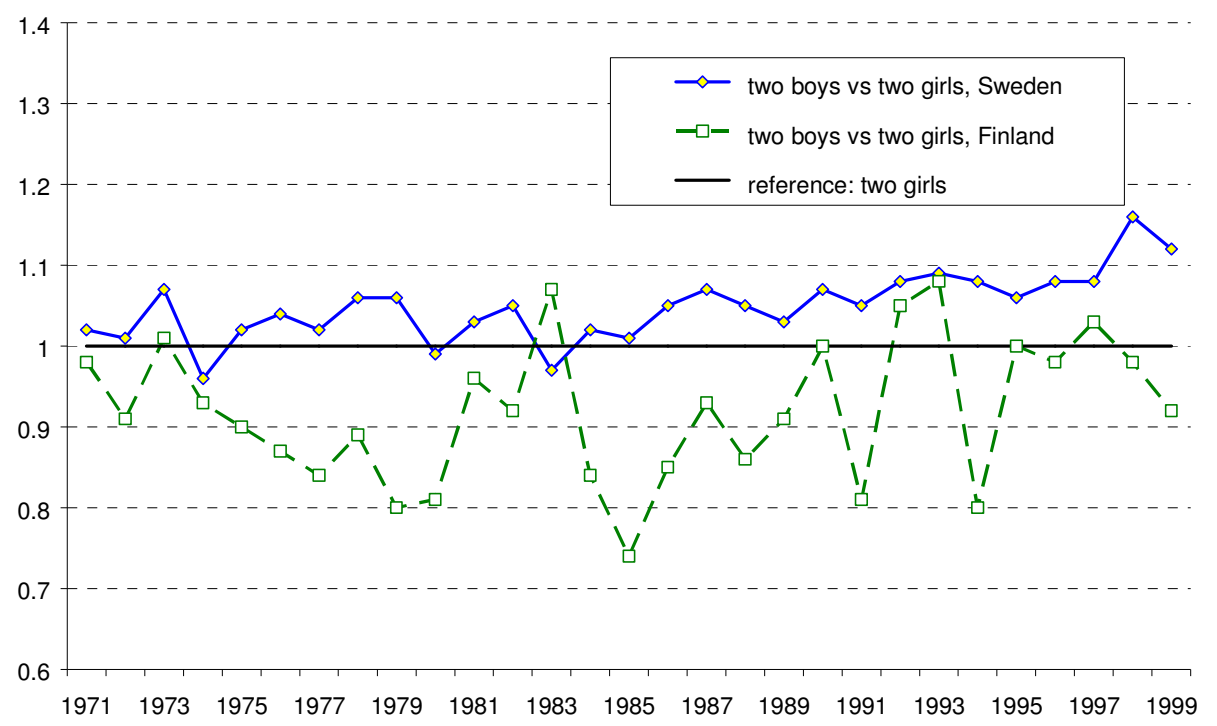


Finally, an in-depth analysis of Finnish-born mothers living in Sweden reveals a significant difference between immigrant women who migrated during their childhood years (i.e., before age 15) and those who migrated as (young) adults; see Table 3. In the latter group, we find exactly the same association between the sex of previous children and continued childbearing that we observed for the Finnish non-migrant population. Mothers who migrated into the Swedish context earlier during their life-course, however, are characterized by a composition preference only, with no gender bias towards sons or daughters.

Table 3: $\quad$ Relative third-birth risk of Finnish-born mothers in Sweden, 197199, by sex of the first two children for women who migrated to Sweden before and after age 15, respectively

\begin{tabular}{lcc}
\hline & Childhood migration & Adult migration \\
\hline Third-birth risks of mothers of: & & \\
- two girls vs one boy and one girl & 1.18 & 1.28 \\
- two boys vs one boy and one girl & 1.19 & 1.18 \\
- two boys vs two girls & $(1.01)$ & 0.92 \\
\hline
\end{tabular}

Source: Swedish population registers, authors' calculations. Results are standardized for calendar year, age of mother, and time since second birth.

Note: effects that are not significant on a five-percent level are given in parentheses.

\subsection{Regional and educational differences in parental sex preferences among the native-born population in Sweden}

In addition to analyzing differences between 'national' majorities and 'ethnic' minorities, our Swedish data set also allows for analyses of regional and educational differences in childbearing dynamics in 1981-1999 as being related to parental gender preferences ${ }^{9}$. These analyses are based on socio-economic and demographic data for cohorts of women born in Sweden in 1945 onwards.

Accounting for information on whether the mother's residence is located in the capital area (Stockholm and its surrounding suburbs) or, for example, in the forested Northern region of Norrland might substantiate speculations about the Finnish boy

\footnotetext{
${ }^{9}$ Unfortunately, such detailed period analyses are not possible on the basis of our smaller sample of Finnish women. However, an inspection of parity-progression rates by educational level and sex of previous children (details not shown here) provides no evidence for differential gender preferences by educational group in Finland: The preference for having a boy appears equally strong for each educational category of Finnish mothers.
} 
preference as being a result of persisting elements of some traditional thinking that attach a higher value to a son (cf. Andersson et al. 2006). If this was the case, one might expect to find a weaker (if any) preference for daughters in the more remote areas of Northern Sweden than in the metropolitan area of Stockholm. However, Table 4 shows that there are no appreciable or systematic regional differences in parental gender preferences (indicated by differential third-birth intensities) between Stockholm, Norrland, and the rest of Sweden. Instead, we see in all regions an almost simultaneous emergence of girl preference from the mid-1980s, which intensified until the very end of our observation period.

Table 4: Relative third-birth risks in Sweden, by sex-composition of the first two children, 1981-99, for women residing in different regions of Sweden in different calendar-year periods

\begin{tabular}{lcccc}
\hline & $1981-85$ & $1986-90$ & $1991-95$ & $1996-99$ \\
\hline Stockholm & & & & \\
- two girls vs one boy and one girl & 1.30 & 1.18 & 1.27 & 1.26 \\
- two boys vs one boy and one girl & 1.30 & 1.33 & 1.33 & 1.44 \\
- two boys vs two girls & $(1.00)$ & 1.13 & 1.05 & 1.14 \\
Norrland & & & & \\
- two girls vs one boy and one girl & 1.32 & 1.17 & 1.20 & 1.32 \\
- two boys vs one boy and one girl & 1.35 & 1.26 & 1.32 & 1.44 \\
- two boys vs two girls & $(1.02)$ & 1.07 & 1.10 & 1.09 \\
Rest of Sweden & & & & 1.22 \\
- two girls vs one boy and one girl & 1.27 & 1.22 & 1.26 & 1.46 \\
- two boys vs one boy and one girl & 1.29 & 1.29 & 1.36 & 1.19 \\
- two boys vs two girls & 1.02 & 1.06 & 1.08 & \\
\hline Source: Swedish population registers, authors' calculations. Results are standardized for age and education of mother and time \\
$\quad$ since second birth. \\
Note: effects that are not significant on a five-percent level are given in parentheses.
\end{tabular}

The 'new' girl preference observed in Sweden might possibly result from a growing share of more highly educated men and women, i.e., from changes in the population composition. Our investigation, however, does not reveal pronounced educational differentials in mothers' sex preferences (Table 5). Still, we observe evidence of a somewhat stronger preference for having a daughter - after having given birth to two boys - among women with secondary or post-secondary education, particularly so in the second half of the 1990s (see Figure 2). These educational differentials are not sufficiently strong, though, to support an argument that the more 
highly educated might have been pioneers of the emerging girl preference during the 1980s. On the contrary, Figure 2 rather suggests a striking similarity across educational groups in the timing of the emerging girl preference in Sweden.

Table 5: Relative third-birth risks in Sweden, by sex-composition of the first two children, 1981-99, for women at different educational attainment in different calendar-year periods

\begin{tabular}{lcccc}
\hline & $1981-85$ & $1986-90$ & $1991-95$ & $1996-99$ \\
\hline Mothers with primary education & & & & \\
- two girls vs one boy and one girl & 1.30 & 1.26 & 1.30 & 1.32 \\
- two boys vs one boy and one girl & 1.32 & 1.32 & 1.38 & 1.40 \\
- two boys vs two girls & $(1.01)$ & 1.04 & 1.06 & 1.07 \\
Mothers with secondary education & & & & \\
- two girls vs one boy and one girl & 1.29 & 1.19 & 1.27 & 1.28 \\
- two boys vs one boy and one girl & 1.35 & 1.29 & 1.38 & 1.51 \\
- two boys vs two girls & 1.05 & 1.08 & 1.08 & 1.18 \\
Mothers with post-secondary education & & & & \\
- two girls vs one boy and one girl & 1.23 & 1.20 & 1.19 & 1.18 \\
- two boys vs one boy and one girl & 1.22 & 1.29 & 1.28 & 1.38 \\
- two boys vs two girls & $(0.99)$ & 1.07 & 1.08 & 1.17 \\
\hline
\end{tabular}

Source: Swedish population registers, authors' calculations. Results are standardized for age and region of residence of mother and time since second birth.

Note: effects that are not significant on a five-percent level are given in parentheses. 
Figure 2: Relative third-birth risks in Sweden, 1981-99, by sex of the first two children for women at different educational attainments in different calendar-year periods. Risks for mothers of two boys and two girls, respectively, by calendar year, relative to the risk of a mother of two girls in 1981 with primary education
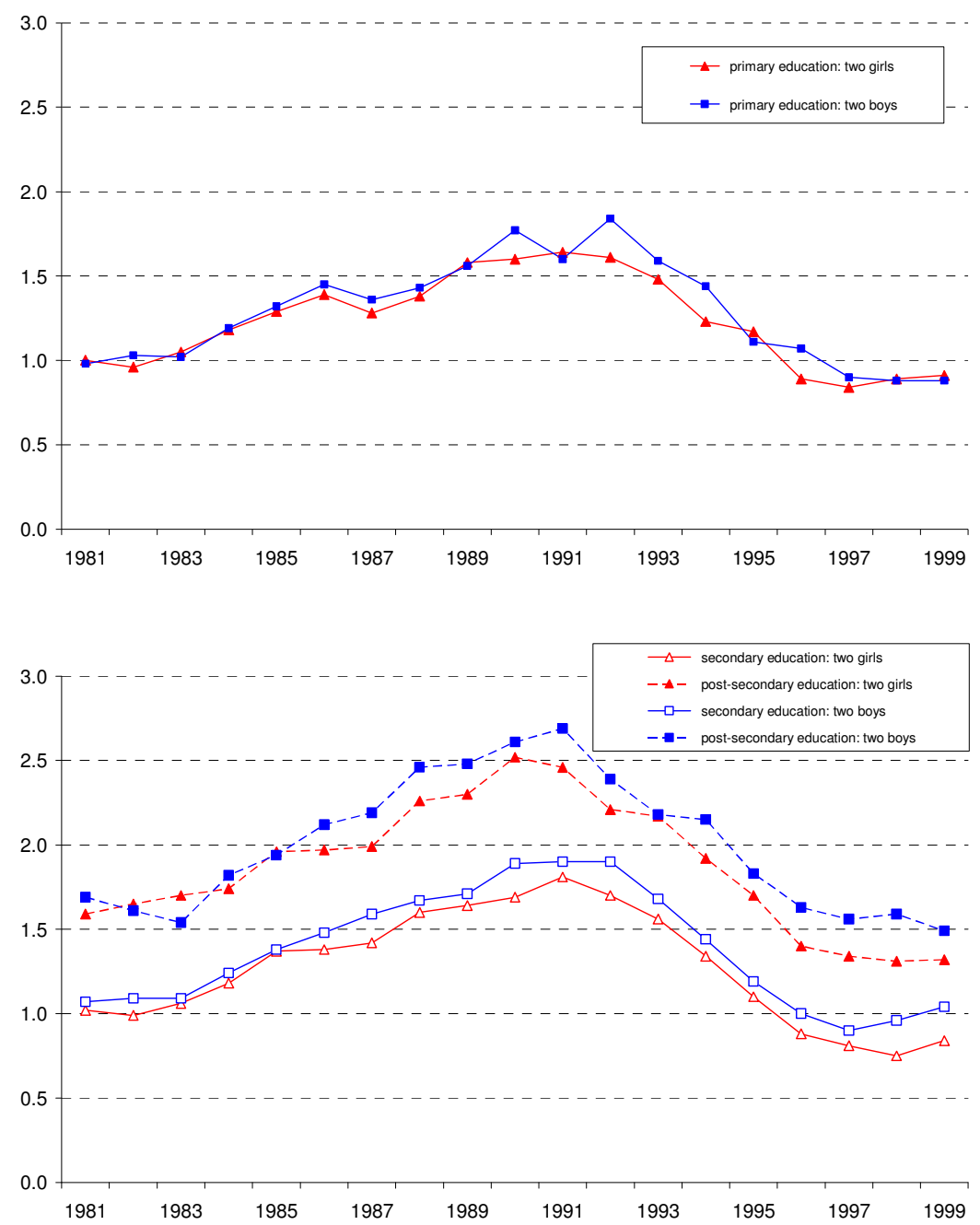


\section{Discussion}

The research presented here aimed to improve our understanding of parental gender preferences in advanced societies, using Finland and Sweden as an example. Generally speaking, our main findings lend support to an interpretation of parental gender preferences as a longstanding cultural phenomenon, which may even persist in the presence of social and economic modernization (cf. Andersson et al. 2006; Hank \& Kohler 2000). This is suggested by the continuing apparent boy preference in Finland during the last decades of the twentieth century - both among the national majority and the Swedish-speaking minority - as well as by similar preferences among Finnish-born migrants in Sweden, where the native population tends to exhibit the opposite preference. That is, even in the absence of the social and institutional forces which may have contributed to shaping their fertility preferences in the Finnish mother country, these migrants have maintained their 'original' sex preferences and did not adopt those present in the Swedish context. However, if the event of migration already occurred during their childhood years, mothers appear to be torn between, on the one hand, social influences they experienced in their family of origin (characterized by 'Finnish' preferences) and, on the other hand, social learning from Swedish peers (and/or nativeborn marriage partners): in this particular group we only detect a 'composition' preference in childbearing dynamics, but no indication for favoring a specific sex.

Apart from this, we find no evidence which supports diffusion theories of differential persistence and change in parents' sex preferences for children. For example, the Swedish girl preference, which fully emerged only in the 1980s, did not occur first in the Stockholm area to develop later in the less urban parts of Sweden, as one might have expected. Instead, our findings are rather in line with Sharlin's (1986: 258) conclusion from the observation of fertility decline during Europe's demographic transition, namely that behavioral change in the first place "occurs in discrete cultural areas (regions) and that urban-rural differentials are subsidiary differences within regions." Our findings suggest that at least in the contemporary Swedish-Finnish context national borders may be more efficient demarcations of such cultural areas than linguistic barriers are (cf. Watkins 1990). Finally, the absence of any evidence suggesting the diffusion of 'new' gender preferences from the more highly educated social strata into the general population of Sweden is consistent with other research on changes in Swedish fertility dynamics by Andersson, Hoem and Duvander (2006), who could not detect any educational differentials in the timing and magnitude of responses to policy measures designed to foster more rapid continued childbearing in Sweden during the 1980s (the so called 'speed premium').

To conclude, parental gender preferences and their impact on fertility decisions (as well as on other family events) may continue to be a demographically relevant topic in 
the twenty-first century. The reasons for the persistence and change in the 'demand' for a specific sex or sex composition of children are still not well understood. What, for example, was the triggering cause of the sudden and (geographically as well as socially) 'global' emergence of girl preference in Sweden? Thus, further - and ideally multidisciplinary - research that helps to improve our understanding of this phenomenon is desirable. Nevertheless, we end with pointing out that the phenomena we have demonstrated still is fairly marginal, which we are able to detect with such precision merely because of the magnitude of our data and with apparent preferences for a child of a specific sex being much weaker than the desire for having a child of each sex. There are no signs that gender preferences for children in the Nordic countries are so strong that they have produced more drastic outcomes like sex-selective abortion (for related evidence from Germany and the U.S., see Dahl et al. 2003; 2006): a closer examination of our data (not shown) reveals that there is no tendency at all of any changes in the sex composition of children born by different demographic sub-groups, neither in Sweden nor in Finland.

\section{Acknowledgements}

Comments by Elizabeth Thomson, Laurent Toulemon, Gerda Neyer, Hill Kulu, and Livia Oláh are gratefully acknowledged. We would also like to thank the Statistical Central Bureaus of Finland and Sweden for providing us with the individual-level register data used in this analysis. 


\section{References}

Andersson, G. (2004): Childbearing after migration: Fertility patterns of foreign-born women in Sweden. International Migration Review, 38 (2), 747-775.

Andersson, G., K. Scott (2005): Labour-market status and first-time parenthood: The experience of immigrant women in Sweden, 1981-97. Population Studies, 59 (1), 21-38.

Andersson, G., K. Scott (2007): Childbearing dynamics of couples in a universalistic welfare state: The role of labor-market status, country of origin, and gender. Demographic Research, forthcoming.

Andersson, G., G. Woldemicael (2001): Sex composition of children as a determinant of marriage disruption and marriage formation: Evidence from Swedish register data. Journal of Population Research, 18 (2), 143-153.

Andersson, G., K. Hank, M. Rønsen, A. Vikat (2006): Gendering family composition: Sex preferences for children and childbearing behavior in the Nordic countries. Demography, 43 (2), 255-267.

Andersson, G., J. Hoem, A.-Z. Duvander (2006): Social differentials in speed-premium effects in childbearing in Sweden. Demographic Research, 14 (4), 51-70, available at http://www.demographic-research.org/Volumes/Vol14/4.

Arnold, F. (1997): Gender preferences for children. Demographic and Health Surveys Comparative Studies No. 23. Calverton, MD: ORC Macro.

Axinn, W., S.T. Yabiku (2001): Social change, the social organization of families, and fertility limitation. American Journal of Sociology, 106 (5), 1219-1261.

Bianchi, S., M. Milkie, L. Sayer, J. Robinson (2000): Is anyone doing the housework? Trends in the gender division of household labor. Social Forces, 79 (1), 191228.

Bongaarts, J. (2001): Fertility and reproductive preferences in post-transitional societies. Population and Development Review, 27, Supplement, 260-281.

Bongaarts, J., S. Watkins (1996): Social interactions and contemporary fertility transitions. Population and Development Review, 22 (4), 639-683.

Brockmann, H. (2001): Girls preferred? Changing patterns of sex preferences in the two German states. European Sociological Review, 17 (2), 189-202. 
Brunborg, H. (1987): Gutt eller jente? Tidsskrift for den Norske Lageforening, 107 (14), 1207-1209

Bulatao, R. (1981): Values and disvalues of children in successive childbearing decisions. Demography, 18 (1), 1-25.

Cleland, J., J. Verrall, M. Vaessen (1983): Preferences for the sex of children and their influence on reproductive behavior. World Fertility Surveys Comparative Studies No. 27. Voorburg, NL: ISI.

Dahl, E., M. Beutel, B. Brosig, K.-D. Hinsch (2003): Preconception sex selection for non-medical reasons: A representative survey from Germany. Human Reproduction, 18 (10), 2231-2234.

Dahl, E., R.S. Gupta, M. Beutel, Y. Stoebel-Richter, B. Brosig, H.-R. Tinneberg, T. Jain (2006): Preconception sex selection demand and preferences in the United States. Fertility and Sterility, 85 (2), 468-473.

Dahl, G.B., E. Moretti (2004): The demand for sons: Evidence from divorce, fertility, and shotgun marriage. NBER Working Paper 10281, Cambridge, MA.

Diekmann, A., K. Schmidheiny (2004): Do parents of girls have a higher risk of divorce? An eighteen-country study. Journal of Marriage and Family, 66 (3), 651-660.

Finnäs, F. (1997): Social integration, heterogeneity and divorce. The case of the Swedish-speaking population in Finland. Acta Sociologica, 40 (3), 263-277.

Finnäs, F. (2003): The Swedish-speaking population on the Finnish labor market. Yearbook of Population Research in Finland, 39, 19-29.

Gray, E.E., A. Evans (2005): Parity progression in Australia: What role does the sex of existing children play? Australian Journal of Social Issues, 40 (4), 505-520.

Hammel, E. (1990): A theory of culture for demography. Population and Development Review, 16 (3), 455-485.

Hammer, M., J. McFerran (1988): Preference for sex of child: A research update. Individual Psychology, 44 (4), 481-491.

Hank, K., H. Jürges (2007): Gender and the division of household labor in older couples: A European perspective. Journal of Family Issues, 28 (3), 399-421.

Hank, K., H.-P. Kohler (2000): Gender preferences for children in Europe: Empirical results from 17 FFS countries. Demographic Research, 2 (1), available at http://www.demographic-research.org/Volumes/Vol2/1. 
Hank, K., H.-P. Kohler (2003): Sex preferences for children revisited: New evidence from Germany. Population (English Edition), 58 (2), 133-144.

Hoffman, L., M.L. Hoffman (1973): The value of children to the parents. In: J. Fawcett (Ed.), Psychological Perspectives on Population, 19-76. New York: Basic Books.

Jacobsen, R., H. Møller and G. Engholm (1999): Fertility rates in Denmark in relation to the sexes of preceding children in the family. Human Reproduction, 14 (4), $1127-1130$.

Kartovaara, L. (1999): Boy or girl? Does it matter and is it a coincidence or destiny? Paper presented at the European Population Conference 1999, The Hague, The Netherlands.

Lundberg, S. (2005): Sons, daughters, and parental behavior. Oxford Review of Economic Policy, 21 (3), 340-356.

Manski, C. (1995): Identification Problems in the Social Sciences. Cambridge, MA: Harvard University Press.

Marleau, J.D., J.-F. Saucier (2002): Preference for a first-born boy in western societies. Journal of Biosocial Science, 34 (1), 13-27.

Montgomery, M., J. Casterline (1996): Social learning, social influence, and new models of fertility. Population and Development Review, 22, Supplement, 151175 .

Morgan, S.P., D. Lye, G. Condran (1988): Sons, daughters and the risk of marital disruption. American Journal of Sociology, 94 (1), 110-129.

Pollard, M., S.P. Morgan (2002): Emerging parental gender indifference? Sex composition of children and the third birth. American Sociological Review, 67 (4), 600-613.

Raley, S., S. Bianchi (2006): Sons, daughters, and family processes: Does gender of children matter? Annual Review of Sociology, 32, 401-421.

SCB (2003): Access to microdata in the Nordic countries. Report, Statistics Sweden, Stockholm. Available online at http://www.micro2122.scb.se/Access_to_ microdata_in_the_Nordic_countries.pdf.

Schullström, Y. (1996): Garçon ou fille? Les préférences pour le sexe des enfants dans les générations suédoises 1946-1975. Population, 51 (6), 1243-1245. 
Seidl, C. (1995): The desire for a son is the father of many daughters. A sex ratio paradox. Journal of Population Economics, 8 (2), 185-203.

Sharlin, A. (1986): Urban-rural differences in fertility in Europe during the demographic transition. In: A. Coale, S. Watkins (Eds.), The Decline of Fertility in Europe, 234-260. Princeton: Princeton University Press.

Sloane, D., C.-F. Lee (1983): Sex of previous children and intentions for further births in the United States, 1965-1976. Demography, 20 (3), 353-367.

Stark, L., H.-P. Kohler (2002): The debate over low fertility in the popular press: A cross-national comparison, 1998-99. Population Research and Policy Review, 21 (6), 535-574.

Svanberg, I., H. Runblom (1988): Det mångkulturella Sverige. En handbok om etniska grupper och minoriteter. Stockholm: Gidluns bokförlag.

Thomson, E. (2001): Value of children. In: N.J. Smelser, P.B. Baltes (Eds.), International Encyclopedia of the Social and Behavioral Sciences, Vol. 8, 17251729. Amsterdam (and others): Elsevier.

Wallgren, A., B. Wallgren (2007): Register-based Statistics: Administrative Data for Statistical Purposes. Chichester: John Wiley and Sons.

Watkins, S. (1990): From local to national communities: The transformation of demographic regimes in Western Europe, 1870-1960. Population and Development Review, 16 (2), 241-272.

Westoff, C. (1999): Mass communications and fertility. In: R. Leete (Ed.), Dynamics of Values in Fertility Change, 237-251. Oxford, USA: Oxford University Press.

Wirth, L. (1938): Urbanism as a way of life. American Journal of Sociology, 44 (1), 124. 
Andersson, Hank \& Vikat: Understanding parental gender preferences in advanced societies 